\title{
Learned adaptations: Teachers' understanding and use of curriculum resources
}

\author{
Jeffrey Choppin
}

Published online: 8 February 2011

(C) Springer Science+Business Media B.V. 2011

\begin{abstract}
This study focused on the use of curriculum materials for three teachers who had enacted instructional sequences from the materials on multiple occasions. The study investigated how the teachers drew on the materials, what they understood about the curriculum resources, and how they connected their use of the materials to their observations of student thinking. There were similarities across the teachers, particularly with respect to their goals and how they read and followed recommendations in the teacher resource materials. There were differences in how their task revisions were in response to what they observed about student thinking. The teacher who most intensively observed student thinking made connections between her interpretations of students' strategies and her use of the curriculum resources, allowing her to design learned adaptations. Learned adaptations required both an understanding of the design rationale and empirically developed knowledge of how that rationale played out in practice. The empirically developed knowledge could not be totally anticipated by the designers, in part because it developed within a particular context by a teacher with particular characteristics. The case of the teacher who developed learned adaptations showed how these complementary forms of knowledge helped her to use the curriculum resources in ways that enhanced students' opportunities for sense making. Furthermore, her adaptations were intended to facilitate success not only at the task level, but also across instructional sequences as well. This study also shows how professional vision is not limited to informing only in-the-moment instructional decisions, but also to the use of curriculum materials.
\end{abstract}

Keywords Teacher learning · Classroom practices · Teacher inquiry · Instructional sequences

J. Choppin $(\bowtie)$

Department of Teaching and Curriculum, The University of Rochester, Dewey Hall 1-160 K,

Box 270425, Rochester, NY 14627, USA

e-mail: jchoppin@warner.rochester.edu 


\section{Introduction}

Teachers' use of innovative mathematics curriculum materials has drawn considerable attention in recent years (Lloyd et al. 2009), particularly with respect to the curriculum programs that were designed to support the instructional recommendations in the National Council of Teachers of Mathematics (NCTM) Standards documents (NCTM 1989, 1991) (hereafter termed Standards-based curriculum programs). Researchers who have attempted to untangle the complex ways that teachers interact with these materials have focused on factors that influence the use of the material, such as teachers' characteristics (Lloyd 1999; Lloyd and Wilson 1998; Remillard and Bryans 2004) and factors in the instructional context (Keiser and Lambdin 1996; Manouchehri and Goodman 1998), as well as the ways in which teachers draw from the materials to design instruction (Collopy 2003; Remillard 1999; Sherin and Drake 2009). While this research has contributed a great deal to our understanding of factors that influence teachers' use of curriculum materials, it has largely left unanswered questions about how the characteristics of these innovative materials ultimately influence teachers' instructional practices, including their use of curriculum materials (Remillard 2009). That is, despite the focus on the potentially educative aspects of innovative curriculum materials (Davis and Krajcik 2005; Remillard 2000), there is little research that focuses on the ways teacher learn from the use of the materials, including learning about the resources in those materials, and how such learning impacts their use of those materials.

In part, the lack of understanding of how characteristics of curriculum resources impact and change teachers' use of curriculum materials is due to the limitations in many studies with respect to the longitudinal aspects of curriculum use. Many of the studies on teachers' use of innovative materials focus on teachers' initial encounters with the materials; given the time frame it typically takes teachers to transform their practices (e.g., Fennema et al. 1996), it is unlikely that such research will be informative with respect to the impact from curriculum resources. Furthermore, if we consider teacher learning in terms of iterative cycles (Simon 1995), one would expect that it would take multiple iterations of the use of curriculum materials before teachers develop an understanding of how students engage with those materials. Consequently, this study focused on three teachers' use of a Standards-based curriculum program in contexts in which the teachers had the opportunity to enact instructional sequences from the program several times prior to the conclusion of the study. The study investigated the ways teachers drew on the resources from the student texts and teacher resource materials, what they learned from the use of the materials, and ultimately whether they adopted the materials in ways that showed an understanding of how the curriculum resources could be used to facilitate student learning.

\section{Research questions}

The study was guided by the following questions:

1. What curriculum use practices were evident after several enactments of instructional sequences from innovative curriculum materials?

2. What teacher knowledge of the curriculum resources was evident, and how did it impact the use of the curriculum materials? 


\section{Framework}

The study builds from the enactment perspective, in which teachers actively interpret and transform curriculum materials as they design instruction (Ben-Peretz 1990; Remillard 2005). Remillard notes that this perspective assumes "that teachers and curriculum materials are engaged in a dynamic interrelationship that involves participation on the parts of both the teacher and the text" (p. 221) and consequently focuses on both the characteristics of teachers and curriculum resources as influential to teacher practices. This perspective stands in contrast to the fidelity perspective, in which "curriculum knowledge is primarily created outside the classroom by the experts who design and develop the curriculum innovation... with teachers implementing the innovation as developed" (Snyder et al. 1992, p. 404). In the enactment perspective, curriculum is created by teachers and students in classrooms, and teacher characteristics and practices play a large role in structuring the interaction between students and curriculum materials.

Research from the enactment perspective emphasizes teacher agency, and consequently seeks to understand differences in the ways teachers interpret and draw from materials as they design instruction. Prior research, for example, focused on teacher characteristics that impact their interpretations and uses of curriculum materials, including teachers' conceptions of how structured student exploration should be (Lloyd 1999), teachers' conceptions of mathematical concepts (Lloyd and Wilson 1998), and teachers' beliefs about the role of curriculum materials in designing instruction (Remillard and Bryans 2004). Research has similarly sought to document and understand differences in the ways teachers draw from the materials to design instruction (Collopy 2003; Remillard 1999; Remillard and Bryans 2004; Sherin and Drake 2009). This research has shown a wide range of practices with respect to curriculum use, suggesting that there is not a direct relationship between the design of curriculum materials and the resulting instructional experiences.

The framework elaborates two central themes related to the enactment perspective. The first is that teachers attend in different ways to resources in curriculum materials, depending upon their beliefs about the role of curriculum materials (Remillard and Bryans 2004), their understanding of the intent and goals underpinning the curriculum (Drake and Sherin 2009), and their ability to understand and use the resources in the materials (Brown 2009). The second theme is that teachers' use of curriculum materials, and their capacity to understand and use resources in those materials, can change as a result of teacher inquiry into how students engage with the materials.

How teachers attend to resources in curriculum materials

The ways teachers attend to curriculum resources is influenced by a range of teacher characteristics related to their beliefs about mathematics teaching and learning, their beliefs about the role of curriculum materials, their strategies and practices around the use of curriculum materials, and their capacity to competently use curriculum materials to enact particular forms of instruction. Researchers have developed terminology to describe these different characteristics, including orientations toward the use of curriculum materials (Remillard and Bryans 2004), curriculum vision (Drake and Sherin 2009), and pedagogical design capacity (Brown 2009), respectively.

Remillard and Bryans (2004) describe how teachers' beliefs about the use of curriculum materials, what they term orientations, are distinct from their beliefs about mathematics teaching and learning, suggesting that teachers develop established practices around the use of curriculum materials irrespective of the resources in the curriculum materials. They 
describe how some teachers used the curriculum materials as a source of tasks without altering their teaching and learning practices, while others adopted a more trusting and adherent view, using the tasks and recommendations in the curriculum materials to more comprehensively guide their instructional practices. Although Remillard and Bryans noted stability in teachers' patterns of curriculum use, they also observed changes in the two teachers who most comprehensively adopted the materials, which suggests that teachers can learn about curriculum resources in ways that impact their practices, a contention explored in more detail later.

As teachers use curriculum resources, they may develop an understanding of the learning opportunities afforded by the materials, or what Drake and Sherin (2009) term curriculum vision. Drake and Sherin suggest that as teachers develop this vision, their curriculum strategies-defined as the ways that teachers read, evaluate, and adapt curriculum materials before, during, and after instruction (Sherin and Drake 2009) - may change. In short, they acknowledge the findings of Remillard and Bryans (2004) that teachers have stable beliefs and practices with respect to curriculum use, but that their curriculum strategies may change as they develop an understanding of the goals and affordances of a set of curriculum materials.

Drake and Sherin (2009) suggest that as teachers change their curriculum strategies they may become more competent in using the materials to enact particular instructional forms, developing what Brown (2009) terms pedagogical design capacity (PDC) with respect to the use of resources in curriculum materials. Brown states that this capacity "represents a teacher's skill in perceiving affordances, making decisions, and following through on plans" (p. 29) with respect to using resources in curriculum materials to design instruction. In particular, PDC represents the teacher's capacity to accomplish "new things" (p. 29), such as enacting curricula in ways that provide coherent and sustained opportunities for students to develop conceptual understanding, ostensible goals of Standards-based curriculum programs.

Brown (2009) states that "if teachers' use of curriculum materials can be understood as a design process, then it follows that some teachers may be more adept than others at designing instructional contexts" (p. 31). In his recommendations to help teachers become more adept at instructional design, Brown focuses on a priori factors related to the interaction between teachers and curriculum materials, such as preparing teachers to better understand the nature of curriculum resources and creating materials whose design features are more apparent (what Davis and Krajcik (2005) term educative curricula), rather than on how the design process itself may develop teachers' PDC. Below, I explore the latter contention in terms of developing teachers' understanding of the affordances of curriculum resources.

Transforming teachers' use of curriculum materials

Remillard and Bryans (2004) observed in their study of teachers' uses of an elementary Standards-based curriculum program that those teachers who most extensively adopted tasks were more likely to learn from the use of the program, with respect to expanding their instructional repertoires, generating insights into student thinking, and constructing the teacher's role in orchestrating student learning, results that indicate that teacher learning is associated with the extent to which teachers draw from the curriculum materials. Although they only observed the first 2 years of the teachers' use of the curriculum, they conjectured that a more longitudinal approach would yield more knowledge about how teachers learn from using curriculum materials. 
Drake and Sherin (2009) describe the connection between curriculum vision and professional vision, which refers to how the discourses and tools of a profession shape the ways professionals make sense of, or notice, complex events (Goodwin 1994). In the case of teachers' use of curriculum materials, curriculum vision refers to teachers' ability to interpret events through the lens of the perceived design features of a curriculum. Drake and Sherin note in ways similar to that of Remillard and Bryans (2004) how teachers' use of curriculum materials changed as a result of enacting the materials, particularly for teachers who developed an understanding of how mathematical ideas developed over instructional sequences in the materials-i.e., curriculum vision. Recent work on professional vision (Sherin 2007; Sherin and Han 2004; Sherin and van Es 2009) and professional noticing (Jacobs et al. 2010) described potential mechanisms by which teachers develop curriculum vision. The research on vision and noticing indicates a range of practices with respect to how teachers attend to student thinking, with some teachers engaging in selective attention that helps them attend to details of students' strategies and ultimately interpret those details in ways that connect students' sense making to instructional practices. These teachers employ knowledge-based reasoning with respect to drawing from the knowledge developed in their own classrooms to transform their practices. In extending the work on professional vision to teachers' use of curriculum materials, Drake and Sherin (2009) imply that teachers who similarly attend to the ways students engage with curriculum materials are likely to develop a better understanding of how the resources and task sequences afford particular learning outcomes and potential trajectories. In time, these teachers may also develop knowledge-based forms of reasoning with respect to the use of curriculum materials, enhancing their pedagogical design capacity.

The outcome of the development of curriculum vision or PDC is the ability to design what I term learned adaptations, which are knowledge-based adaptations designed with respect to what teachers have learned from prior enactments. Learned adaptations involve an understanding of how curriculum resources can be used to design instruction with respect to particular instructional outcomes, such as fostering opportunities for students to develop conceptual understanding through active engagement in mathematical processes. Teachers' understanding of curriculum resources in this case does not develop only from reading the resource materials or from participating in professional development that highlights the curriculum's design features, but also from applying professional vision to systematic inquiry in their own classrooms about the ways student engage with and learn from the curriculum materials. This process is similar to what Cochran-Smith and Lytle (1999) terms an inquiry stance, in which:

The knowledge that teachers need to teach well is generated when teachers treat their own classrooms and schools as sites for intentional investigation at the same time that they treat the knowledge and theory produced by others as generative material for interrogation and investigation. (p. 250)

In the case of teachers' curriculum use, an inquiry stance involves attending to student thinking and to the curriculum's design rationale, which offers the 'knowledge and theory produced by others' for teachers to consider as they make sense of what students are doing. Teachers who engage in learned adaptations adopt curriculum materials in the sense that they go beyond simply following the prescribed curriculum in using the resources to facilitate the teaching and learning practices they envision. 
Table 1 Teachers and the instructional units in which they were observed

\begin{tabular}{|c|c|c|c|c|c|}
\hline \multirow[t]{2}{*}{ Teacher } & \multirow[t]{2}{*}{ Grade } & \multirow[t]{2}{*}{ Unit } & \multirow[t]{2}{*}{ Topic of sequence } & \multicolumn{2}{|c|}{$\begin{array}{l}\text { Number of times } \\
\text { teaching unit }\end{array}$} \\
\hline & & & & $\begin{array}{l}\text { New } \\
\text { version }\end{array}$ & $\begin{array}{l}\text { Old } \\
\text { version }\end{array}$ \\
\hline Birman & 8 th & $\begin{array}{l}\text { Growing, growing, } \\
\text { growing }\end{array}$ & Exponential relationships & $3^{\mathrm{a}}$ & 2 \\
\hline Rothschild & 7 th & Comparing and scaling & Comparisons and unit rates & 3 & 3 \\
\hline Wright & 6 th & Comparing and scaling & Comparisons and unit rates & 2 & 1 \\
\hline Wright & 6 th & Accentuate the negative & Integer addition and subtraction & $3^{\mathrm{b}}$ & 3 \\
\hline
\end{tabular}

\footnotetext{
${ }^{a}$ Birman was also observed and interviewed in her first enactment of the new version, interviewed before and after her second enactment, and observed and interviewed after her third enactment

b Wright was interviewed with her planning partner the following year as well, in which she reflected on the 4 th enactment of the unit
}

\section{Methods}

The study focused on three teachers' use of materials from the Connected Mathematics Project (CMP) curriculum program (Lappan et al. 1998, 2006). The teachers were videotaped enacting instructional units from the materials and then interviewed about those enactments, explained in more detail later.

\section{Selection of teachers}

The three teachers, all white women, were selected because they were experienced users of the CMP curriculum (minimum of 5 years of experience at the conclusion of the study), had participated in extensive professional development around the use of the curriculum program, and had enacted the instructional units in which they were observed at least three times prior to the conclusion of the study. See Table 1 for a list of the teachers and the units in which they were observed.

A single unit for each teacher was chosen for analysis with the exception of Wright, ${ }^{1}$ for whom two units were chosen. She was selected for two units because preliminary analysis showed that she was more attentive to student thinking than Birman and Rothschild and because her practices across the two units varied. Birman and Wright taught in the same district that drew students from socioeconomic backgrounds that were relatively higher than most of the nearby districts, including the one in which Rothschild taught. The school where Rothschild taught was under review for poor student performance on standardized tests at the time of the study. All three teachers expressed strong support for the use of CMP and the associated instructional practices, which was another criterion in selecting the teachers.

\section{Curriculum materials}

The CMP materials emphasize student exploration in challenging tasks as a means of developing mathematical content (Lappan and Phillips 2009). Each CMP unit is divided

\footnotetext{
1 The names of all of the teachers are pseudonyms and are the names of women mathematicians whose biographies are listed on the website http://www.agnesscott.edu/Lriddle/women/women.htm.
} 
into four to five investigations, each of which consists of a task situation or context that serves to organize the investigation and several problems related to the same concept. Each investigation is intended to follow a launch-explore-summary format. The launch serves to familiarize students with the context and the mathematics as a means of priming student activity in the subsequent exploration, in which students engage with a task that usually is accessible to multiple approaches, which then become the focus of the summary portion of the task. The summary portion allows for various solutions to be compared and for the teacher to emphasize the important mathematical aspects of the tasks. Typically, the first investigation of a unit includes a series of tasks in which the primary goal is to get students thinking about the key ideas in the unit, but in which little formalization is expected to occur. In CMP, the expectation is that students will not achieve mastery of a skill or concept at the end of each investigation, but instead students will develop formalized and conventional understanding after a progression of activities that allow time (usually 4 weeks or more for each unit) for exploration and gradual development of concepts (Lappan et al. 2004, p. 17).

\section{Data collection}

The research team created Unit Sets using the video data, modifying the teaching set methodology (Simon and Tzur 1999; Cobb et al. 2009), which involves videotaping multiple lessons and using specific events or practices observed in those lessons as the basis of teacher interviews. The Unit Sets consisted of six to ten videotaped class sessions, usually consecutive, as well as a pre-unit interview and a post-unit video-stimulated interview. The pre-unit interviews focused on a teacher's perceptions of the main instructional goals for the unit, the primary challenges she anticipated in terms of enacting the instructional sequences in the unit, and the key tasks and representations that facilitated the learning trajectories within the instructional sequences. The class sessions were recorded from the beginning of the unit in order to capture how key concepts, representations, and procedures were introduced and developed over the course of two to three investigations. The video-stimulated interviews were based on a set of about 10 episodes, ranging from three to $15 \mathrm{~min}$ in length, selected by the researcher to provoke reflection about instructional sequences in the unit. The episodes were selected to represent: instructional practices frequently observed in the teacher's class; a range of tasks in the unit, in order to have the teacher explain the role of each task and any strategies observed when enacting the tasks; and enactments of the summary discussions, to gauge the teachers' insights into the discussions. I generated a series of specific questions around each clip and compiled the questions and the video clips, which I provided to the teacher. After the teacher had an opportunity to preview the clips, I conducted a semi-structured interview that lasted typically 60-90 min. Each interview began with questions about the goals and main learning challenges for the unit before addressing the questions about the specific episodes. In 2010, I conducted a joint interview with Wright and her planning partner, in which I asked them to reflect on the 2010 enactment of Accentuate the Negative. Finally, all of the teachers were interviewed prior to the study about their more general experiences with the CMP curriculum.

\section{Data analysis}

The unit of analysis in terms of the curriculum materials was an instructional sequence, which consists of a sequence of tasks and the potential learning trajectories afforded by the 
task sequence (Carpenter et al. 2004). An instructional sequence differs from a CMP unit in that it is usually focused on a fairly narrow mathematical domain, such as adding and subtracting integers; consequently, a CMP unit may have more than one instructional sequence. Below, I describe the two primary categories for data analysis.

\section{Curriculum use}

Remillard (2005) defines curriculum use as the ways in which "individual teachers interact with, draw on, refer to, and are influenced by material resources designed to guide instruction" (p. 212). Consequently, I developed two broad categories of codes, use of curriculum resource materials and adaptations. The 'curriculum resource' codes included how teachers interpreted the goals for their respective instructional sequences, their use of the teacher resources, and the extent to which they followed instructional recommendations in the teacher resources, especially with regard to structuring student activity and following the launch-explore-summary lesson format. The 'adaptation' codes included the extent to which they omitted or supplemented tasks, the frequency of adaptations, and the purposes for those adaptations.

\section{Curriculum vision}

There were three sub-categories intended to characterize key features of teachers' curriculum vision. The first sub-category involves the teachers' understanding of the resources in the curriculum materials, such as how the teachers described tasks, tasks features, and task sequences. For example, I looked at how the teachers described task features and how those features were related to mathematical concepts. I also looked at the ways the teachers described the mathematical progression across the tasks. The second sub-category was attention to student thinking, in which codes involved a continuum of practices derived from the research on professional vision (e.g., Sherin and van Es 2009). The teachers' references to students' strategies were coded in terms of evaluating student strategies, describing the details of those strategies, and interpreting students' strategies in terms of how those strategies indicated how students were making sense of mathematical concepts. The third sub-category involved the ways in which teachers connected their understanding of the curriculum resources to their interpretations of how students were making sense of mathematical concepts.

\section{Results}

There were some important similarities across the teachers' uses of curriculum materials and their curriculum vision. The teachers, for example, generally stated similar goals for their respective instructional sequences in terms of student sense making around mathematical concepts. They also generally read and followed the instructional recommendations and description of mathematical goals in the teacher resources. None of the teachers omitted tasks from the student materials and there were only a couple of instances in which the teachers added supplemental tasks. Furthermore, each teacher described in considerable detail curriculum resources, including task features and representations and how those resources connected to the mathematical goals of the unit.

There were important differences, too. The extent to which the teachers adapted tasks differed across the teachers and across the two sequences enacted by Wright; furthermore, 
the reasons given for those adaptations differed as well. Perhaps the most striking differences were found in the ways the teachers attended to student thinking and the how they connected their interpretations of student thinking to their descriptions of the curriculum resources. Wright, for example, extensively described student strategies and interpreted those strategies with respect to how students were making sense of mathematical concepts, particularly in the Accentuate the Negative unit, while Birman and Rothschild more frequently evaluated students' strategies rather than providing details of those strategies. Furthermore, Wright made strong connections between her interpretations of student sense making and the ways she described and used the curriculum resources, connections that were less evident with Birman and Rothschild. Below, I expand on these findings by describing the results for each category.

\section{Teachers' curriculum use}

The results related to the teachers' curriculum use are summarized in Tables 2 and 3 . The results in Table 2 show how the teachers described the goals for their respective instructional sequences, the extent to which they followed the recommended instructional practices, and the ways they used the teacher resource materials.

\section{Goals for the instructional sequences}

The teachers emphasized mathematical content when they described their goals for their respective sequences, but also indicated the importance of sense making and, in the case of

Table 2 Use of curriculum resource materials

\begin{tabular}{|c|c|c|c|}
\hline Teacher & Goals & $\begin{array}{l}\text { Followed recommended } \\
\text { practices }\end{array}$ & Use of teacher resources \\
\hline Birman & $\begin{array}{l}\text { Have students understand } \\
\text { exponential relationships } \\
\text { through various } \\
\text { representations }\end{array}$ & $\begin{array}{l}\text { Consistently followed 3-part } \\
\text { lesson structure, including } \\
\text { extensive time for group } \\
\text { exploration }\end{array}$ & $\begin{array}{l}\text { Read the TE to identify } \\
\text { important concepts, for ideas } \\
\text { to structure student activity, } \\
\text { and to identify key questions } \\
\text { for explore and summary } \\
\text { lesson segments }\end{array}$ \\
\hline Rothschild & $\begin{array}{l}\text { Have students make sense of } \\
\text { comparisons, make } \\
\text { connections between } \\
\text { different comparisons, and } \\
\text { knowing when comparisons } \\
\text { are appropriate }\end{array}$ & $\begin{array}{l}\text { Followed 3-part lesson } \\
\text { structure most of the time, } \\
\text { though sometimes deviated } \\
\text { from it to save time }\end{array}$ & $\begin{array}{l}\text { Read TE for key questions } \\
\text { before most lessons }\end{array}$ \\
\hline $\begin{array}{l}\text { Wright- } \\
\text { CS }\end{array}$ & $\begin{array}{l}\text { Have students makes sense of, } \\
\text { analyze and generate a range } \\
\text { of comparisons, using a } \\
\text { variety of strategies }\end{array}$ & $\begin{array}{l}\text { Consistently followed 3-part } \\
\text { lesson structure, including } \\
\text { extensive time for group } \\
\text { exploration }\end{array}$ & $\begin{array}{l}\text { Read TE to identify key } \\
\text { questions and concepts to } \\
\text { highlight in summary portion } \\
\text { lesson and to anticipate } \\
\text { student strategies. Studied } \\
\text { TE before enacting unit }\end{array}$ \\
\hline $\begin{array}{l}\text { Wright- } \\
\text { AN }\end{array}$ & $\begin{array}{l}\text { Have students develop sensible } \\
\text { strategies, make sense of and } \\
\text { understand connections } \\
\text { between integer addition and } \\
\text { subtraction }\end{array}$ & Same as for CS & Same as for CS \\
\hline
\end{tabular}


Table 3 Frequency of and purposes for changes in tasks

\begin{tabular}{|c|c|c|c|}
\hline Teacher & $\begin{array}{l}\text { Extent of omitting/ } \\
\text { supplementing }\end{array}$ & Frequency of adaptations & Reasons for adaptations \\
\hline Birman & $\begin{array}{l}\text { No omissions. Supplementing } \\
\text { involved two introductory } \\
\text { tasks designed to make } \\
\text { connections to linear and } \\
\text { quadratic relationships }\end{array}$ & $\begin{array}{l}\text { In addition to two } \\
\text { supplemental tasks, Birman } \\
\text { altered several charts, } \\
\text { tables, and graphs }\end{array}$ & $\begin{array}{l}\text { Focus students on finding } \\
\text { growth factor and starting } \\
\text { value and using those } \\
\text { parameters to write general } \\
\text { form of exponential equation }\end{array}$ \\
\hline Rothschild & $\begin{array}{l}\text { No omissions or } \\
\text { supplementing }\end{array}$ & $\begin{array}{l}\text { Infrequent and minor } \\
\text { adaptations, with the } \\
\text { exception of task in which } \\
\text { she skipped the explore } \\
\text { phase }\end{array}$ & $\begin{array}{l}\text { Primarily to reduce demand of } \\
\text { tasks or to save time }\end{array}$ \\
\hline $\begin{array}{l}\text { Wright- } \\
\text { CS }\end{array}$ & $\begin{array}{l}\text { No omissions. Added a new } \\
\text { introductory task }\end{array}$ & $\begin{array}{l}\text { Infrequent and minor } \\
\text { adaptations }\end{array}$ & $\begin{array}{l}\text { Recruit students' interest; } \\
\text { focus students on } \\
\text { manageable set of } \\
\text { comparisons }\end{array}$ \\
\hline $\begin{array}{l}\text { Wright- } \\
\text { AN }\end{array}$ & $\begin{array}{l}\text { No omissions. Supplementing } \\
\text { involving an introductory } \\
\text { task on defining integers and } \\
\text { a later task focused on } \\
\text { student conjectures }\end{array}$ & $\begin{array}{l}\text { Frequently adapted tasks } \\
\text { across the instructional } \\
\text { sequence }\end{array}$ & $\begin{array}{l}\text { Focus students on models and } \\
\text { representations that helped } \\
\text { students connect addition } \\
\text { and subtraction; focus } \\
\text { students on their conjectures } \\
\text { and use of language }\end{array}$ \\
\hline
\end{tabular}

Wright, having students explain their strategies. Birman's goals for Growing emphasized understanding exponential relationships and how they are evident across a range of representations, with a particular emphasis on the general form of the equation. She described the goals of the unit as being able "to identify an exponential relationship, create the table, develop the equation... and also compare similarities and differences between an exponential function and linear function" (Video-stimulated interview [VSI], 10/08/2008). Rothschild described the goals for Comparing and Scaling in terms of a range of mathematical topics and of students being able to distinguish when to use particular comparisons. She stated the goals as:

proportional reasoning... ratios, and thinking of part to part versus part to whole, relating it to fractions and setting up proportions, learning how to solve proportions, relating it to their percent work which then gets into comparing fractions, decimals and percents... being able to...think about which strategies are best to use for certain types of problems. (Pre-Unit Interview [PUI], 10/29/2008)

Wright similarly described the goals for Comparing and Scaling as "being able to make comparisons using ratios, percents, fractions, differences in rates and knowing when one of those types of comparisons is more appropriate than others," while stating that "I hope they have a good sense of proportional reasoning" (VSI, 12/10/2009). For Accentuate the Negative, Wright stated that "a big part of that is seeing the connection between the adding and subtracting," adding that "want them to understand ... to become efficient at a strategy that makes sense to them" (Joint Interview [JI] 03/25/2010). She stated that "they should ... have a variety of strategies... [and] to explain what they're doing and how they're doing it" (PUI 01/15/2009). 


\section{Following recommended practices}

The teachers generally followed the three-part structure for the investigations and other recommendations from the teacher resources. Birman and Wright sometimes broke up the investigations into two parts, covering each part in the launch-explore-summary format. In one instance, Rothschild enacted a task in a whole class format, skipping the explore segment, in order to save time. The teachers generally followed the activity structures (e.g., pairs, groups) and other suggestions for facilitating student work in the explore phase, and the summaries generally included presentations of student strategies, as recommended in the teacher resources.

\section{Use of teacher resource materials}

The teachers used the teacher editions (TEs) to identify the main ideas and key questions identified by the designers as the focus for a particular investigation. Birman stated that the TE "gives me a good idea of questions to ask for discussions... what are the good points that the authors wanted to bring out in that investigation" (Background Interview [BI], 11/27/2006). Birman gave a couple of specific examples of suggestions from the TE that she had implemented. Rothschild stated that the TE "does help with a lot of the questions ... that you can ask to help guide kids without usually giving them the answer ... those probing questions that ... are really helpful" (VSI, 03/18/2009). Wright stated that she used the TE primarily to guide her summary discussions, saying that "I use the TE a lot to definitely look at the ideas ... I should be bringing out... the questions, or ...what kids might say and different strategies" (BI, 12/05/2006).

The results in Table 3 describe changes that teachers made in the task designs. The three categories include the extent to which the teachers omitted or supplemented tasks, the frequency with which they revised tasks, and the purposes they provided for those adaptations.

\section{Omitting or supplementing}

The teachers did not omit any of the tasks from the student text and supplemented in only two of the instructional sequences. Birman added two tasks at the beginning of the Growing unit to help students see the differences between linear, quadratic, and exponential patterns. In one of the tasks, for example, she had students compare two prizes in a lottery, one based on a linear growth pattern and the other on an exponential growth pattern. Wright added introductory tasks in both of her sequences. For Accentuate the Negative, for example, she introduced a task in which she asked students to define integers. She stated that the goal for the supplemental tasks was to help students begin thinking and talking about the key ideas of the upcoming instructional sequence.

\section{Frequency and purpose of adaptations}

The teachers varied with respect to the frequency with which they revised the written tasks and the reasons they cited for doing so. Birman's adaptations focused primarily on two representations. First, she expanded a chart for an expanded calculation that she hoped would help students to make the connection between the number of times a number appeared as a factor and the exponent of the simplified term, an adaptation she said came from a suggestion from a workshop. Second, she designed a chart that showed the first four 
exponential patterns introduced in the instructional sequence. She stated that she wanted students to compare the patterns to identify the growth factor and starting value, the parameters for the general form $\left(a^{*} b^{x}\right)$ of an exponential equation. She stated that the goal of her adaptations were to make it easier for the students to generate the general form.

Rothschild had two notable adaptations. In the first, she tried to have students evaluate a range of comparison statements in a whole class format, without providing time for students to work in groups. She stated that her goal was to "just read and discuss it as a class ...they don't need to spend a lot of time ... we can get through that quickly." She noted, however, that "they definitely needed time to think about the statements ....it was too quick" (VSI, 03/18/2009). In the second adaptation, she modified a task to limit the number of comparison students had to create, saying that "they tend to struggle with actually making the comparison statements themselves ...so we said each pair would write two statements," ultimately noting that "they struggled ...I guess maybe it didn't simplify it enough for them" (VSI, 03/18/2009).

Wright's only notable adaptation in the Comparing and Scaling unit involved the same task as Rothschild's second adaptation. She stated that it was difficult to give feedback on all of the comparison statements, stating "they all write three different comparison statements .... and so they're wanting to know if theirs is true and you can't spend the time going over every single one" (PUI, 03/26/2009). So, she first had students compare each other's statements, during which she circulated around the room, typing at least one comparison statement of each type she observed, and then had the class collectively reflect on those comparison statements. In the Accentuate the Negative unit, Wright made five notable adaptations, some of which will be described in more detail later. The adaptations stemmed from Wright' observations in prior enactments that indicated that students struggled to make key connections and that led to difficulties in students' ability to generate coherent and efficient strategies; consequently, the adaptations were intended to help students generate and attend to conjectures about the patterns students noticed about integer addition and subtraction.

Teachers' curriculum vision

The results that describe the teachers' curriculum vision, summarized in Table 4, are organized according to three characteristics, the teachers' understanding of the curriculum resources, their attention to student thinking, and the connections they make between their understanding of the curriculum resources and their interpretations of student thinking.

\section{Teachers' understanding of curriculum resources}

The teachers' understanding of the curriculum resources was characterized by the ways they talked about the mathematical concepts in the instructional sequences, task features, and how the task features and sequences were intended to help students engage with the mathematical concepts. Birman, for example, described the main ideas in Growing as distinguishing between linear and exponential relationships, understanding the notions of growth factor and starting value, finding values for growth factor and starting value, and associating those values with parameters in the general form of an exponential equation. She described how task features, like tables and graphs, helped students to recognize exponential patterns and to determine the growth factor and starting values. She stated that "I think it is very important for them to use the table to get that equation, you know, to get that pattern ...I [learned that] just reading the resources ... [the curriculum designers] are 
Table 4 Teachers' curriculum vision

\begin{tabular}{|c|c|c|c|}
\hline Teacher & $\begin{array}{l}\text { Understanding of curriculum } \\
\text { resources }\end{array}$ & Attention to student thinking & $\begin{array}{l}\text { Connecting curriculum } \\
\text { resources to student thinking }\end{array}$ \\
\hline Birman & $\begin{array}{l}\text { Described curriculum } \\
\text { resources and mathematical } \\
\text { goals, though she expressed } \\
\text { uncertainty about how the } \\
\text { resources helped students } \\
\text { make mathematical } \\
\text { connections }\end{array}$ & $\begin{array}{l}\text { Almost exclusively evaluated } \\
\text { students' strategies, } \\
\text { providing few specifics of } \\
\text { details of those strategies }\end{array}$ & $\begin{array}{l}\text { Made almost no connection } \\
\text { between curriculum } \\
\text { resources, use of those } \\
\text { resources, and how students } \\
\text { were making sense of } \\
\text { mathematical ideas. } \\
\text { Adaptations were } \\
\text { speculative }\end{array}$ \\
\hline Rothschild & $\begin{array}{l}\text { Described mathematical ideas } \\
\text { and some curriculum } \\
\text { resources, but provided few } \\
\text { details of how resources } \\
\text { helped students }\end{array}$ & $\begin{array}{l}\text { Evaluated student strategies } \\
\text { and provided details of those } \\
\text { strategies }\end{array}$ & $\begin{array}{l}\text { Made minimal connections } \\
\text { between curriculum } \\
\text { resources, use of those } \\
\text { resources, and how students } \\
\text { made sense of mathematical } \\
\text { ideas }\end{array}$ \\
\hline $\begin{array}{l}\text { Wright- } \\
\text { CS }\end{array}$ & $\begin{array}{l}\text { Described mathematical ideas } \\
\text { and curriculum resources, } \\
\text { and how resources helped } \\
\text { students make important } \\
\text { connections }\end{array}$ & $\begin{array}{l}\text { Provided extensive } \\
\text { descriptions of student } \\
\text { strategies, especially in } \\
\text { Orange Juice problem, and } \\
\text { students' strategic } \\
\text { preferences }\end{array}$ & $\begin{array}{l}\text { Described how tasks afforded } \\
\text { opportunities for students to } \\
\text { attend to different } \\
\text { comparisons and to } \\
\text { distinguish between } \\
\text { multiplicative and additive } \\
\text { strategies }\end{array}$ \\
\hline $\begin{array}{l}\text { Wright- } \\
\text { AN }\end{array}$ & $\begin{array}{l}\text { Described mathematical ideas } \\
\text { and curriculum resources, } \\
\text { and how resources helped } \\
\text { students make important } \\
\text { connections; also noted } \\
\text { progression across tasks }\end{array}$ & $\begin{array}{l}\text { Provided extensive } \\
\text { descriptions of student } \\
\text { strategies, and interpreted } \\
\text { those details in terms of } \\
\text { student sense making of } \\
\text { integer addition and } \\
\text { subtraction }\end{array}$ & $\begin{array}{l}\text { Justified task adaptations in } \\
\text { terms of how students made } \\
\text { sense of concepts in past } \\
\text { enactments; critiqued design } \\
\text { of curriculum in light of } \\
\text { interpretation of student } \\
\text { sense making }\end{array}$ \\
\hline
\end{tabular}

always referring back to the table for the pattern" (VSI 01/09/2007). In reference to the doubling pattern created when a piece of paper is repeatedly folded in half to make ballots, she noted that the table helps students to see "the patterns... what's happening to our y-value after each cut ... realizing that you're multiplying, not adding” (PUI 02/16/2007). She also noted how the graphs would help students find the value of the "y-intercept...just like we use it in our linear or quadratic" (UI 02/16/2007). At times, however, Birman was uncertain about how the curriculum resources helped students to understand exponential relationships and to generate equations. For example, in relation to finding the y-intercept from graphs, Birman ignored issues around scale that might make it difficult to read the $\mathrm{y}$-intercept from a graph, especially in cases like $a^{\mathrm{x}-1}$, where $a>1$, a form that represented the first four patterns in the task sequence. In these cases, the y-intercept was between zero and one, making it hard to read the value accurately from the graph. In other cases, Birman repeatedly expressed her concerns about the students' ability to understand that exponents can vary and that exponential relationships involved multiplicative rather than additive patterns. She also expressed her doubts that students could find the starting value for the general form of an exponential equation, especially in cases in the first investigation where the starting value was not evident in the context of the problem. Consequently, although Birman described the mathematical content and task features in detail, she did not explain how the task features facilitated or impeded student learning. 
Rothschild described the mathematical concepts in Comparing and Scaling, such as the different kinds of comparisons (e.g., percents, fractions, and ratios), the emphasis on part to part and part to whole comparisons, unit rates, and proportions, and how these concepts were sequenced. She described the progression:

In the beginning you're given the comparison statements and you're asked ... 'are they related, how are they related, could things that look different be equivalent, be the same?' ... and then it moves on to using the ratios and the percents... to analyze different situations, and then it moves on to ...make a table, essentially using a unit rate and scaling ... and in the end it kind of ties up with 'okay, now everything that you've learned is sort of this idea of things being in proportion and can you actually now set up actual proportions and use all the things you've learned to solve them.' (VSI, 03/18/2009)

She described the goals of the sequence as distinguishing between additive and multiplicative forms of reasoning and to "identify the different ways that ratios can be written ... [and to] use various strategies in the language of ratios" (PUI, 10/29/2008). She stated that a ratio expressed "idea of equivalence, that even though something is changing, some things got to stay the same" (PUI, 10/29/2008). For example, in the Orange Juice problem, "we tried to say, you know, "well what if I double it or what if I triple it will it taste the same' but look what's happening to the difference" (VSI, 03/18/2009). She described the role of specific tasks, stating that one of the initial tasks helped to "introduce the comparison statements to provide that real world connection and give students an opportunity to actually analyze the written statements and make comparisons" (VSI, 03/18/2009). Rothschild, like Birman, described the mathematical content and task features in detail, but provided little description of how the task features might help students develop an understanding of the mathematics.

Wright similarly described the mathematics in Comparing and Scaling, but provided more detail than Birman and Rothschild in terms of the task features and the progression of mathematics across the task sequence. She described, for example, the purpose of the opening tasks, which was to help students grapple with questions such as " "what do these statements mean?', 'where did these numbers come from?', 'what does one statement tell you versus another?', ... 'what do you get from a difference that you can't get from other forms of representation?'” (PUI, 03/26/2009). She stated that while the early tasks helped to familiarize students with different kinds of comparisons, the Orange Juice problem provided an opportunity for students to decide on the appropriateness of certain comparisons. She stated that the Orange Juice problem was "the big problem of the unit....[the students] have got to come up with a way to make these comparisons...to figure out which one is the most orangey, which one is the least orangey [without] much direction at all" (VSI, 12/10/2009). She also noted that the Orange Juice problem helped to problematize the part to part and part to whole comparisons, stating the students need to see "which one really would have the most orange concentrate when we're not comparing the same part" (PUI, 03/26/2009). Similarly, she stated how the Pizza problem also problematized the notion of whole when making comparisons, stating that "what's different about [the Pizza problem] is that we're looking at a comparison in which it's like a part to part but they're parts of different wholes, so we're talking about pizzas to people" (VSI, 12/10/2009). Wright described the unit rate problems in terms of the importance of making sense of the rate:

You have 10 oranges for two dollars so it makes them what's the cost per orange and then how many oranges could you buy for a dollar so you look at the two different 
unit rates and what do those two different rates mean... which one makes more sense to you, which one would help you more and for them to see that in certain cases one unit rate makes sense, in another case another unit rate might make more sense to you depending on what you need the information for. (PUI, 03/26/2009)

Wright had a similarly detailed description of the resources and progression in Accentuate the Negative. She described the role of early tasks as getting students to informally work with integers in familiar contexts. She stated that the initial tasks gave students "a way to jump into negative numbers in something that's a familiar context ... something they intuitively understand" (VSI 06/02/2009). The second problem involves a thermometer, which is "something familiar to them... it's basically working on a number line" (PUI 01/15/2009). She noted the importance of the chip board and number line models as important resources. She stated that the students "constantly talk about which way they're moving on a number line and how they end up in ... the positive and the negatives" (JI 03/25/2010). With respect to the chip board, she noted "they related [their computation] back to putting on and taking off numbers in the chipboard... they made that connection" (PUI 01/15/2009). She noted that tasks early in the sequence facilitated the development of number sentences that helped students connect integer addition and subtraction, while latter tasks helped students to generate and refine patterns based on their earlier work. For example, a latter task involves students describing patterns in two groups of addition problems, noting that thinking about the patterns "takes them away from talking necessarily about a number line or a chip board model" (VSI 06/02/2009). Wright stated that, subsequently, the students develop and refine conjectures, with the goal of developing efficient strategies. She stated that "the conjectures are basically patterns and generalizations that they're noticing ... whereas when they write the algorithm it's what steps they take to solve problems" (JI 03/25/2010). She described the algorithms as a cumulative product, saying "the vocabulary that they used and what they were saying, they didn't miss cases...they were really talking well about the math" (JI 03/25/2010). Wright not only described the mathematical content and task features, but she also explained how task features provided opportunities for students to reason about the mathematical content.

\section{Connecting curriculum resources to student thinking}

There were some stark differences across the teachers in terms of the ways they described student thinking and how they connected those descriptions to their understanding and use of the curriculum resources. To varying degrees, all three teachers evaluated student thinking and described details of the strategies students produced. However, each teacher had a predominant practice when it came to discussing student thinking. Birman, for example, primarily evaluated student thinking in terms of whether students understood something or were able to generate a particular value or representation. Her evaluations were evenly split in terms of whether they positively or negatively evaluated student thinking. For example, with respect to finding the parameters of the general form for an exponential equation, she stated "the kids were able to identify each piece right away, what the $a$ was, where the $b$ came from" (UI 03/16/2007). She noted that students quickly understood the multiplicative nature of the pattern from the ballot problem, saying "they see it's not going up by two, four, six, eight, that it's actually doubling, they see that real quick" (PUI 02/16/2007). Conversely, she described how students had difficulty with a pattern similar to the ballot problem, but in which the number of times that 'two' appeared as factor was one less than the term number, meaning the table had the appearance of 
shifting the y-values down one slot. She stated that "I think they'll be okay, until we get to the Ruba plan...everything gets shifted down, and then they get lost" (UI 03/16/2007). Similarly, she described students' struggles to generate an equation, saying "once they're given a separate problem to do that's different, they struggle...they can tell me, 'oh it's doubling' or 'it's tripling,' ... but they can not get it into that form" (VSI 10/04/2007).

Birman did not explain how her evaluations of student thinking were related to her use of the curriculum materials. Her reasons for adapting tasks had a speculative tone. For example, in explaining why she intended to emphasize graphs in a subsequent enactment, she stated that:

They understood it was the y-intercept, but I don't think they fully understood it. So I felt like maybe bringing in the graph they'll be able to see that it actually crosses the y-axis...because I didn't have it there for them to visually see that it's crossing the y-axis, so maybe that would be better. (PUI 02/16/2007)

She provided no evidence for why she thought students would make the connection between the graphical features and the equation parameters in ways different or better than using the table had. More generally, Birman provided no evidence from past enactments to support how she revised tasks, except to note that the prior task versions had been ineffective and that a change was needed.

Rothschild also primarily evaluated student thinking, attributing students' difficulties to their lack of basic skills, motivation, or persistence. She described, for example, students' difficulties in understanding comparisons:

I asked them 'can you give me an example of a part to part comparison?' and they're still struggling... I say 'okay, how many girls are in the class, how many boys are in the class, is that a part to part, or part to whole'...and maybe it's just they don't pay attention to, you know, maybe they're just not invested to pay attention to the details... but I'm finding this is a huge struggle understanding the difference between a part to part and a part to whole. (VSI, 03/18/2009)

At times, Rothschild provided the details of student strategies, especially for the Pizza problem. For example, she stated that "some kids divided the pizza and they understood this is how much of a pizza each person gets, and a couple kids split it into 8 pieces" (VSI, 03/18/2009). However, she did not connect these strategies to how students made sense of mathematical concepts or to her use of the curriculum materials. She justified task adaptations by citing the need to reduce the difficulty of tasks, though she offered no explanation as to how her adaptations would help students develop mathematical understanding. She was uncertain about how her use of the curriculum materials helped students learn, saying "I struggle with how to help them see the connections ... me just telling them well there's the connection... that doesn't always work ...that's not going to help them internalize it, remember it and ... apply it" (VSI, 03/18/2009).

Across both instructional sequences, Wright described students' strategies in more detail than the other two teachers. Furthermore, she frequently interpreted those details in terms of student sense making. For example, she described a strategy from the Orange Juice problem in which students compared concentrate to water rather than concentrate to the entire mixture:

They'll say two cups concentrate to three cups water... 66 and $2 / 3$ percent concentrate, because they're looking at a part to part and changing it to a percent ...I see a problem [if] they said that it's 66 and $2 / 3$ percent concentrate because that's not 
true...The kids will automatically go "no, no, it works...it still comes out to be the most orangey if we do it that way.' So then we go back and we look at 'okay, you're dividing two by three... when we take a percent what are we looking at?' So I make kids go back and look at it and then eventually I try to get them to see that it is okay to say that as a percent but what you're saying is that the concentrate is 66 and $2 / 3$ percent of the water. (PUI, 03/26/2009)

Wright connected students' strategies to how they were interpreting percents as a part to part rather than the typical part to whole. However, in her account, she did not correct the students, but rather helped them make sense of their strategies. In Accentuate the Negative, Wright described how a student made the connection between adding a positive integer and subtracting a negative integer:

George ... was the one that said 'if you are subtracting a positive you go to the left on a number line, so it has to be going in the opposite direction. So if you're subtracting a negative you have to be going to the right.' So that's how he made a connection that, 'oh instead of saying I'm adding 10 I could say I'm subtracting negative $10 \ldots$ that's another way I could write that number sentence.' (VSI 06/02/2009)

Wright explained how the student's strategy was evidence of an important connection in the instructional sequence, similar to other examples from each instructional sequence in which Wright described the details of strategies and connected those strategies to student sense making.

Wright's tendency to relate her use of the curriculum materials to student sense making represented a distinction between her practices and those of Birman and Rothschild, a distinction that merits further examination. Below, I explore a number of adaptations from the Accentuate the Negative unit to provide further detail into the ways Wright used evidence from prior enactments to inform her use of the materials. I focus the discussion only on Accentuate the Negative for coherence and because Wright more actively revised tasks in that sequence, providing greater opportunities to examine how she justified her adaptations.

\section{Adaptations for Wright in Accentuate the Negative}

In order to explore in more detail Wright's use of the materials in the Accentuate the Negative sequence, I describe four adaptations, focusing on how the adaptations emerged from Wright's observations of student thinking in prior enactments.

\section{The temperature change problem}

The temperature change problem occurred relatively early in the instructional sequence. Prior to this task, students had worked with problems in which they informally computed with integers, and this task extended the focus on developing number sentences that represented situations. The instructions in the student text for the temperature change problem read Sketch a number line and write number sentences for each question, and the students were given scenarios and asked to find the change in temperature, such as: $A$ person goes from a sauna at $120^{\circ} \mathrm{F}$ to an outside temperature of $-20^{\circ} \mathrm{F}$. What is the change in temperature? Wright noted that the intended number sentence was $120+-$ $140=-20$, but that students often said " 'I go 120 on the number line to get to zero then I go 20 more on the number line to get to negative 20 ,' so they'll write things like 120 plus 
20 equals 140," (VSI 06/02/2009), which she stated did not represent the situation. So, Wright, in conjunction with her planning partner, provided more explicit instructions about what to write, saying "We have a place for them to write how they solved the problem and then we had them write the number sentence to represent the problem" (JI 03/25/2010). Wright noted the impact of the adaptation, saying it:

helped bring out different ways to represent the same problem... the next questions were ... about the differences, why we're getting two number sentences in some and only one in others. When they write things that don't represent the problems you're not going to see the connectedness between those number sentences. (VSI 06/02/2009)

\section{Chip board problem}

Wright noted that her adaptation of the temperature change problem helped her revise how she introduced the chip board model. She stated that she wanted to make sure the students' actions and number sentences represented the situation described in the task. In past enactments, students would "figure out the [answer] and then they go back and try to represent it on chip board" (VSI 06/02/2009), a process that yielded inaccurate or meaningless actions. She revised the instructions to be more explicit and described an ensuing episode:

It was negative three take away five. I had kids that... would just put on the five red [to get eight red chips] and I said, 'but it says you're taking away, and I don't see anywhere in your picture on your chipboard where you're taking away.' 'Oh, cause taking away means subtracting,' and ... they would be like 'but that doesn't work with red and like well it's a positive five, okay that's black chips.'(JI 03/25/2010)

Wright found that by helping students accurately connect their actions to number sentences, students continued to make connections with the chip board, saying:

Later on in the unit, kids started talking-without me saying a word about the chipboard - they started talking about subtracting a negative they would say 'it's like on the chipboard model when we want to take away the negative and there wasn't any there we really were putting on black and red and then we took off the red so basically we were just putting on the black. (JI 03/25/2010)

\section{Conjectures}

One of the tasks added by Wright involved collecting and recording students' conjectures, so that students had the opportunity to explicitly consider the patterns they had observed in the early part of the sequence. She stated that "kids would be noticing things, but they wouldn't necessarily have anywhere to say it...so I started it as 'let's collect' and then we would go back and we would edit it" (VSI 06/02/2009). She added that she did it to "to start formalizing those patterns they see... there's so much that they're doing that they don't necessarily stop and realize that these are patterns" (VSI 06/02/2009).

\section{Grouped subtraction problems}

One of the tasks leading up to the formal development of algorithms was a task in which students had to consider their strategies for subtracting integers. In the student text, the 
subtraction problems were divided into two groups, one in which the operands had like signs and in the other unlike signs. Wright noted that this grouping deflected student attention from the operations they had been using to subtract integers earlier in the sequence. She noted that for some students "that's not how they're going to talk about their strategies... there's different ways you could think about it ...this kind of forces kids into strategies" (JI 03/25/2010). Consequently, she ungrouped the problems to let students decide how to group the problems, though she noted that many students "still ended up on four cases ... they still kept it positive minus positive, negative minus negative,..." (JI 03/25/2010).

These adaptations were designed in response to students' strategies Wright observed in prior enactments. The adaptations were not simply a response to the perceived failure or success of a task, but to specific ways that students had engaged with the tasks. Furthermore, the adaptations were designed to make important connections, to generate strategies, or to reflect on strategies or conjectures students had already developed. The adaptations served purposes that extended beyond the scope of the individual tasks and that were intended to provide opportunities for students to develop their own strategies and ways of thinking about mathematical topics.

\section{Discussion}

The results show that the teachers' understanding of the curriculum resources impacted how they used those resources and that the teacher with the most profound understanding showed the greatest impact. Although Birman and Rothschild showed knowledge of the mathematical content and task features in the curriculum materials, they showed little understanding of how the resources helped students learn. Wright, by contrast, showed knowledge of the features of the curriculum and how they functioned as resources to help students learn, knowledge that informed her use of the materials. Below, I characterize the teachers' understanding and use of the curriculum materials in terms of curriculum vision and how that vision impacted their use of the resources.

Birman's and Rothschild's vision included an articulation of the designers' intent (i.e., the kinds of learning and teaching activities that the designers intended), the mathematics emphasized in particular sequences, and task features. However, they did not develop an understanding of how the task features and sequences helped students understand the mathematical concepts emphasized in the sequence. Although their adaptations represented conjectures about what might help students generate particular outcomes, such as comparison statements or the general form of an exponential equation, the adaptations did not emerge from knowledge-based reasoning about how students engaged or made sense of the mathematics emphasized in the task features. Wright, by contrast, articulated a curriculum vision that not only included an articulation of the designers' intent, the mathematics, and the task features, but also of how the task features afforded opportunities for students to engage with mathematical concepts. Furthermore, through close observation of student thinking, she developed knowledge-based reasoning around the use of the materials. Her understanding of how students engaged with task features in prior enactments informed how she adapted tasks in subsequent enactments, especially in the Accentuate the Negative unit.

How did Wright's curriculum vision impact her practice? This question addresses a key conjecture about how curriculum materials are educative-i.e., how the curriculum resources impact teachers' use of curriculum materials. In the cases of Birman and Rothschild, it was less clear how the resources impacted their practice. Although they 
followed recommended practices from the curriculum materials and structured their classrooms in ways that represented a departure from conventional practices is U.S. classrooms, it was unclear what they learned from the curriculum materials. They expressed frustration at their lack of understanding of how the materials facilitated the kinds of student outcomes they sought, suggesting that their vision ultimately had little impact on their use of the materials beyond following the prescribed sequence and instructional format. Wright's practices, on the other hand, were influenced by the resources in the curriculum materials. She adapted tasks based on how student thinking developed within and across tasks in the instructional sequence; consequently, her observations and conjectures about student learning were situated with respect to how students engaged with particular task features and sequences. Although she adapted tasks, she stated that her adaptations were aligned with the designers' intentions. She intentionally followed the written materials as a script in the first one or two enactments, saying the "first year we taught (Accentuate the Negative) ... they were brand new materials so we kind of dedicated ourselves, 'let's just do it all and go through it' ...we were figuring it out as we went" (JI 03/25/2010). Her adaptations were intended not to facilitate student success within a particular task, but to facilitate the development of thinking across the instructional sequence, which required an understanding of how the resources provoked particular strategies or ways of reasoning. These results indicate the interaction between curriculum vision and PDC. As Wright's curriculum vision developed, so did her capacity to use the resources in ways that enhanced students' opportunities to learn.

These results extend the work on curriculum vision, particularly how it relates to professional vision. The work on professional vision has primarily focused on the ways teachers interpret student thinking irrespective of particular curriculum sequences (e.g., Sherin and van Es 2009; Jacobs et al. 2010). Extending this work involves looking at how teachers' attention to student thinking informs their use of curriculum materials in ways leading to learned adaptations. Birman and Rothschild's attention to student thinking could be characterized as 'evaluating' student thinking or, at best, describing details of student thinking, practices that did not inform their adaptations. Wright, by contrast, consistently provided details and, more importantly, interpreted those details in terms of how students were making sense of the mathematics. Her knowledge-based reasoning, however, was not limited strictly to informing her in-the-moment instructional decisions, but also longerterm planning practices related to the use of the curriculum materials.

An interesting result from this study was how Wright adapted tasks more frequently in Accentuate the Negative than in Comparing and Scaling. This occurred for perhaps two reasons. The first reason is that Wright had enacted the Accentuate the Negative unit at least one time more and consequently had increased opportunity to observe how students engaged with the materials. The second reason is that she felt that Accentuate the Negative was a messier unit in terms of how she saw the progression of student thinking across tasks. Wright commented how she adapted tasks in some units very little compared to others, in part because she felt the materials as written accomplished her goals. In other cases, she felt that it was less obvious how the materials recruited forms of student reasoning that were productive for developing understanding of the mathematical concepts that were the goals of the unit.

Factors in the instructional context were not explicit topics of this study, though it was clear that they mattered. All of the teachers had extensive professional development around the CMP materials and had access to the full array of curriculum resource materials, things that the teachers identified as valuable and helpful. There were clear differences in terms of opportunities for collaboration. Wright had a productive collaborative relationship with her 
planning partner. She described how they had similar philosophies, would intensively discuss the mathematics and student strategies, and would thoroughly study together the student text and teacher resources before teaching a unit. Birman also described regular collaboration with her primary planning partner, though she described the focus on their interactions as mostly around planning and logistics and less about inquiry into the materials or student thinking. Rothschild, by contrast, bemoaned the lack of opportunity for collaboration in her school over the years, stating that the district's curriculum policies had gradually de-emphasized the CMP curriculum and associated instructional approaches. This also pointed to the generally favorable policy environments for Wright and Birman and the less favorable one for Rothschild, whose school faced sanctions and consequently was focused on increasing test scores.

\section{Conclusion}

This study contributes to the field's understanding of how a teacher may adopt curriculum resources in ways that build from and extend the designers' intentions. Wright showed a deep awareness of the curriculum resources in ways that indicated her understanding of the design rationale and how that rationale played out in practice. Prior descriptions of the educative nature of curriculum materials were all situated within an articulation of the design rationale — and teachers' reading of it—as the primary source of teacher learning (Ball and Cohen 1996; Davis and Krajcik 2005). By contrast, learned adaptations suggest both an understanding of the design rationale and empirically developed knowledge of how that rationale plays out in practice. The empirically developed knowledge cannot be totally anticipated by the designers, in part because it is developed within particular contexts by teachers with particular characteristics. However, the case of Wright shows how this complementary form of knowledge is vital to enacting curriculum materials in ways that promote student learning. Her learned adaptations amplified the curriculum resources in ways that enhanced students' opportunities for sense making and for participation in the collective development of conceptual understanding, goals emphasized in the CMP materials.

\section{Questions for future research}

Future research should focus on how teachers' vision varies across mathematical content. Wright's practices differed across the two instructional units; furthermore, she stated that units that emphasized algebra required less revision because the development of algebraic representations was more straightforward than developing understanding of proportional reasoning or of integer computation. Future research should also elaborate how teachers' use of the teacher resources changes as they enact curriculum materials, particularly whether they read them to resolve dilemmas rather than just to familiarize themselves with task features.

\section{References}

Ben-Peretz, M. (1990). The teacher-curriculum encounter: Freeing teachers from the tyranny of texts. Albany: State University of New York Press. 
Brown, M. (2009). The teacher-tool relationship: Theorizing the design and use of curriculum materials. In J. T. Remillard, B. Herbel-Eisenmann, \& G. Lloyd (Eds.), Mathematics teachers at work: Connecting curriculum materials and classroom instruction (pp. 17-36). New York: Routledge.

Carpenter, T. P., Blanton, M. L., Cobb, P., Franke, M. L., Kaput, J., \& McClain, K. (2004). Scaling up innovative practices in mathematics and science (Research report). Madison, WI: National Center for Improving Student Learning and Achievement in Mathematics and Science.

Cobb, P., Zhao, Q., \& Dean, C. (2009). Conducting design experiments to support teachers' learning: A reflection from the field. Journal of the Learning Sciences, 18(2), 165-199.

Cochran-Smith, M., \& Lytle, S. L. (1999). Relationships of knowledge and practice: Teacher learning in communities. Review of Research in Education, 24, 249-305.

Collopy, R. (2003). Curriculum materials as a professional development tool: How a mathematics textbook affected two teachers' learning. The Elementary School Journal, 103(3), 287-311.

Davis, E., \& Krajcik, J. (2005). Designing educative materials to promote teacher learning. Educational Researcher, 34(3), 3-14.

Drake, C., \& Sherin, M. G. (2009). Developing curriculum vision and trust: Changes in teachers' curriculum strategies. In J. T. Remillard, B. Herbel-Eisenmann, \& G. Lloyd (Eds.), Mathematics teachers at work: Connecting curriculum materials and classroom instruction (pp. 321-337). New York: Routledge.

Fennema, E., Carpenter, T. P., Franke, M. L., Levi, L., Jacobs, V. R., \& Empson, S. B. (1996). A longitudinal study of learning to use children's thinking in mathematics instruction. Journal for Research in Mathematics Education, 27(4), 403-434.

Goodwin, C. (1994). Professional vision. American Anthropologist, 96(3), 606-633.

Jacobs, V. R., Lamb, L. L. C., \& Philipp, R. (2010). Professional noticing of childrens' mathematical thinking. Journal for Research in Mathematics Education, 41(2), 169-202.

Keiser, J. M., \& Lambdin, D. V. (1996). The clock is ticking: Time constraint issues in mathematics teaching reform. The Journal of Educational Research, 90, 23-31.

Lappan, G., Fey, J. T., Fitzgerald, W. M., Friel, S. N., \& Phillips, E. D. (1998). Connected mathematics. Palo Alto, CA: Dale Seymour Publications.

Lappan, G., Fey, J. T., Fitzgerald, W. M., Friel, S. N., \& Phillips, E. D. (2004). Getting to know connected mathematics: An implementation guide. Needham, MA: Pearson Prentice Hall.

Lappan, G., Fey, J. T., Fitzgerald, W. M., Friel, S. N., \& Phillips, E. D. (2006). Connected mathematics 2. Boston, MA: Prentice Hall.

Lappan, G., \& Phillips, E. (2009). A designer speaks. Educational Designer, 1(3). Retrieved from http:// www.educationaldesigner.org/ed/volume1/issue3/article11.

Lloyd, G. (1999). Two teachers' conceptions of a reform-oriented curriculum: Implications for mathematics teacher development. Journal of Mathematics Teacher Education, 2, 227-252.

Lloyd, G., Remillard, J. T., \& Herbel-Eisenmann, B. (2009). Teachers' use of curriculum materials: An emerging field. In J. T. Remillard, B. Herbel-Eisenmann, \& G. Lloyd (Eds.), Mathematics teachers at work: Connecting curriculum materials and classroom instruction (pp. 3-14). New York: Routledge.

Lloyd, G., \& Wilson, M. S. (1998). Supporting innovation: The impact of a teacher's conceptions of functions on his implementation of a reform curriculum. Journal for Research in Mathematics Education, 29(3), 248-274.

Manouchehri, A., \& Goodman, T. (1998). Mathematics curriculum reform and teachers: Understanding the connections. Journal of Educational Research, 92(1), 27-41.

National Council of Teachers of Mathematics. (1989). Curriculum and evaluation standards for school mathematics. Reston, VA: Author.

National Council of Teachers of Mathematics. (1991). Professional standards for teaching mathematics. Reston, VA: Author.

Remillard, J. T. (1999). Curriculum materials in mathematics education reform: A framework for examining teachers' curriculum development. Curriculum Inquiry, 29(3), 315-342.

Remillard, J. T. (2000). Can curriculum materials support teachers' learning? Two fourth-grade teachers' use of a new mathematics text. The Elementary School Journal, 100(4), 331-350.

Remillard, J. T. (2005). Examining key concepts in research on teachers' use of mathematics curricula. Review of Educational Research, 75(2), 211-246.

Remillard, J. T. (2009). Considering what we know about the relationship between teachers and curriculum materials. In J. T. Remillard, B. Herbel-Eisenmann, \& G. Lloyd (Eds.), Mathematics teachers at work: Connecting curriculum materials and classroom instruction (pp. 85-92). New York: Routledge.

Remillard, J. T., \& Bryans, M. B. (2004). Teachers' orientations toward mathematics curriculum materials: Implications for teacher learning. Journal for Research in Mathematics Education, 35(5), 352-388. 
Sherin, M. G. (2007). The development of teachers' professional vision in video clubs. In R. Goldman, R. Pea, B. Barron, \& S. Derry (Eds.), Video research in the learning sciences (pp. 383-395). Hillsdale, NJ: Lawrence Erlbaum.

Sherin, M. G., \& Drake, C. (2009). Curriculum strategy framework: investigating patterns in teachers' use of a reform-based elementary mathematics curriculum. Journal of Curriculum Studies, 41(4), 467-500.

Sherin, M. G., \& Han, S. Y. (2004). Teacher learning in the context of a video club. Teaching and Teacher Education, 20, 163-183.

Sherin, M. G., \& van Es, E. A. (2009). Effects of video club participation on teachers' professional vision. Journal of Teacher Education, 60(1), 20-37.

Simon, M. A. (1995). Reconstructing mathematics pedagogy from a constructivist perspective. Journal for Research in Mathematics Education, 26(2), 114-145.

Simon, M., \& Tzur, R. (1999). Explicating the teachers' perspective from the researcher' perspectives: Generating accounts of mathematics teachers' practice. Journal for Research in Mathematics Education, 30(3), 252-264.

Snyder, J., Bolin, F., \& Zumwalt, K. (1992). Curriculum implementation. In P. W. Jackson (Ed.), Handbook of research on curriculum (pp. 402-435). New York: Macmillan. 